\title{
Biochemical markers of type 2 diabetes as a late complication of myocardial infarction: a case-control study
}

Olga Barbarash, Olga Gruzdeva, Evgenya Uchasova, Ekaterina Belik, Yulia Dyleva, Victoria Karetnikova

Federal State Budgetary Scientific Institution Research Institute for Complex Issues of Cardiovascular Diseases, Kemerovo, Russia

Submitted: 2 December 2014

Accepted: 25 February 2015

Arch Med Sci 2017; 13, 2: 311-320

DOI: https://doi.org/10.5114/aoms.2017.65240

Copyright (C) 2017 Termedia \& Banach

\section{Abstract}

Introduction: On average, $19-23 \%$ of patients with acute myocardial infarction (MI) suffer from type 2 diabetes mellitus, which is newly diagnosed in a significant number of patients. Both classic carbohydrate metabolism and lipid metabolism may be promising diagnostic markers for insulin resistance in acute coronary syndrome.

Material and methods: Two hundred patients (130 males and 70 females aged $61.4 \pm 1.12$ years) with ST-segment elevation MI were included in the study. Patients were divided into two groups based on manifestations of diabetes: (1) 171 patients without diabetes within 1 year after MI; and (2) 29 patients with manifestations of diabetes. The control group comprised 33 people without diseases of the cardiovascular system and diabetes and was matched by age and gender with patients.

Results: In patients with an imbalanced adipokine state during the acute phase of MI, we noted an increased concentration of free fatty acids $(p>0.05)$ and reduced ghrelin levels $(p>0.05)$ and activation of the proinflammatory and thrombotic potentials of blood plasma. Patients who developed diabetes 1 year after MI showed hospital stays with more pronounced changes in the study parameters.

Conclusions: The most informative biochemical parameters associated with the development of diabetes at 1 year after MI were adiponectin, retinol protein, ghrelin, tumor necrosis factor $\alpha$, and plasminogen activator inhibitor.

Key words: type 2 diabetes mellitus, adipokines, ghrelin, tumor necrosis factor $\alpha$, myocardial infarction.

\section{Introduction}

Acute coronary syndrome (ACS) continues to be associated with a high incidence of in-hospital and post-hospital discharge complications [1]. On average, $19-23 \%$ of patients with acute myocardial infarction (MI) suffer from type 2 diabetes mellitus, which is newly diagnosed in a significant number of patients $[2,3]$. The percentage of ACS patients with previously and newly diagnosed diabetes is $45-53 \%$, and the percentage with impaired glucose tolerance is $20-36 \%$ [3]. An increased risk of death for diabetic patients with acute $\mathrm{MI}$ may persist for several years.
Corresponding author: Evgenya Uchasova PhD Federal State Budgetary Scientific Institution Research Institute for Complex Issues of Cardiovascular Diseases 6 Sosnovy Bvild. St 650002 Kemerovo, Russia Phone: +7 (3842) 64-05-53 E-mail: evg.uchasova@ yandex.ru 
Both classic carbohydrate metabolism (hyperglycemia and hyperinsulinemia) and lipid metabolism may be regarded as promising diagnostic markers for insulin resistance in ACS. Lipid metabolism disorders are considered major risk factors for the development and progression of cardiovascular disease $[4,5]$. Among lipid metabolism parameters in ACS, the most significant forms are those that involve cholesterol transport and free fatty acids (FFA), which provide up to $70 \%$ of the energy requirements for myocardium and reflect typical pathological patterns occurring in the ischemic/necrotic area and, therefore, are associated with functional impairment of cardiac muscle [6] The importance of studying FFA is because of their participation in the development of insulin resistance [7, 8], hyperglycemia, diabetes manifestation (in which endothelial dysfunction results in macro- and microangiopathy), impairment of cardiovascular activity, and the initiation of early and late cardiovascular complications in $\mathrm{MI}[6,8]$.

Besides the classical parameters of carbohydrate metabolism that are considered diagnostic markers of insulin resistance, lipid metabolism parameters and their regulators should also be included, these being adipokines, inflammation and thrombogenesis [9-11]. The investigation of possible pathogenic associations between the studied parameters may be important for understanding the fundamental mechanisms and manifestations of diabetes, and may be a theoretical basis for risk stratification of ACS complications and improvement of quality of life in patients with previous MI. This study aimed to identify the most significant parameters of carbohydrate and lipid metabolism, adipokines and proinflammatory and prothrombogenic states associated with the development of diabetes 1 year after MI.

\section{Material and methods}

Two hundred patients (130 males and $70 \mathrm{fe}$ males aged $61.4 \pm 1.12$ years) with ST-segment elevation MI were included in the study. Patients were divided into groups based on the manifestation of diabetes in the late $\mathrm{Ml}$ period: group 1 $(n=171)$ without diabetes in the late Ml period; and group $2(n=29)$ with diabetic manifestations 1 year after MI. The control group included 33 participants without cardiovascular diseases and diabetes and was comparable in age and gender to the enrolled patients (Table I).

The study protocol was approved by the local ethics committee of the Federal State Budgetary Scientific Institution Research Institute for Complex Issues of Cardiovascular Diseases, developed in accordance with the WMA Declaration of Helsinki "Ethical principles for medical research in- volving human subjects" (amended in 2000) and "Rules for clinical practice in the Russian Federation", approved by the Ministry of Health of the Russian Federation in 19 June 2003. All patients provided written informed consent to participate in the study.

Inclusion criteria were acute ST-segment elevation $\mathrm{MI}$, confirmed according to the principles of the All-Russian Scientific Society of Cardiology (2007), and admitted to the hospital within $24 \mathrm{~h}$ after the onset of symptoms. Exclusion criteria were previously or newly diagnosed type 2 diabetes at the time of the index event, severe diseases affecting prognosis (anemia, renal and hepatic failure, cancer, acute infectious and inflammatory diseases), autoimmune diseases, long-term corticosteroid therapy and death during either the in-hospital or the post-hospital (within 12 months) period. A limitation of the study was the lack of measurement of uric acid levels and parameters of physical activity.

All patients in the absence of contraindications during the in-hospital period received combined coronaroactive, antithrombotic and lipid-lowering therapy, including aspirin, clopidogrel, $\beta$-blockers, angiotensin convertase enzyme (ACE) inhibitors, statins and antiangina medications in accordance with standard clinical practice. Reperfusion therapy included primary percutaneous coronary intervention of the infarct-dependent artery, performed in 181 (90.5\%) patients, and systemic thrombolysis with streptokinase $1.5 \mathrm{MIU}$ in 12 (6\%) patients.

Adverse outcomes after $\mathrm{Ml}$ included reinfarction, worsened angina, decompensated heart failure and requirement of hospitalization within the 1-year follow-up.

A structured mathematical model was used to assess insulin resistance levels at days 1 and 12 based on fasting plasma insulin and glucose values and by calculating the QUICKI (Quantitative Insulin Sensitivity Check Index) [11] according to the following formula: QUICKI $=1 /\left[\log \left(I_{0}\right)+\log \right.$ $\left(G_{0}\right)$ ], where $I_{0}$ is basal insulinemia $(\mathrm{mMU} / \mathrm{ml})$, and $G_{0}$ is basal glycemia $(\mathrm{mg} / \mathrm{dl})$. Katz et al. reported that an average QUICKI value of $0.382+0.007$ corresponds to normal tissue sensitivity to insulin; and a QUICKI value of $0.331+0.010$ and 0.304 +0.007 correspond to moderate and severe tissue insulin resistance, respectively [12].

An oral glucose tolerance test (OGTT) was performed to verify diabetes during the in-hospital period (on day 12) and 1 year after $\mathrm{MI}$ according to the algorithms of specialized medical care [9]. Fasting glycemia was measured in patients after 3 days of an unrestricted diet, with the last uptake being 30-50 g of carbohydrates. Plasma glucose was determined $2 \mathrm{~h}$ after administration of a 75-g glucose-containing solution, consumed over 3-5 min. 
Patients were not allowed to smoke during OGTT. Postprandial glycemia was measured when the fasting glycemia level was $\geq 7.8 \mathrm{mmol} / \mathrm{l}$ ( $2 \mathrm{~h}$ after a meal containing 20-24 g of carbohydrates, $6.9 \mathrm{~g}$ of protein and $8.11 \mathrm{~g}$ of fat). Diagnostic criteria for diabetes according to WHO recommendations (1999-2006) were fasting venous plasma glucose $\geq 7.0 \mathrm{mmol} / \mathrm{l}$ or $2 \mathrm{~h}$ after OGTT/postprandial $\geq 11.1 \mathrm{mmol} / \mathrm{l}$ glycated hemoglobin $\left(\mathrm{HbA}_{1 \mathrm{c}}\right)$ level $\geq 6.5 \%$ [9].

\section{Assays}

Blood serum and plasma were tested. Serum was separated from venous blood by centrifugation at $3000 \times \mathrm{g}$ for $20 \mathrm{~min}$ and stored at $-70^{\circ} \mathrm{C}$. FFA, total cholesterol (TC), triacylglycerols (TAG), low-density lipoprotein (LDL-C), very-low-density lipoprotein (VLDL-C), apolipoprotein B (apo B), high-density lipoprotein (HDL-C) and apolipoprotein A1 (apo A1) levels were measured at the same

Table I. Initial clinical and anamnestic characteristics of patients

\begin{tabular}{|c|c|c|c|}
\hline Variable & $\begin{array}{c}\text { Patients without } \\
\text { type } 2 \text { diabetes }(n=171)\end{array}$ & $\begin{array}{l}\text { Patients with first diagnosed } \\
\text { type } 2 \text { diabetes }(n=29)\end{array}$ & $P$-value \\
\hline Men, $n(\%)$ & $107(63.0)$ & $23(79.0)$ & 0.20 \\
\hline Age [years] & $62.58 \pm 1.2$ & $59.5 \pm 2.2$ & 0.30 \\
\hline \multicolumn{4}{|l|}{ Clinical measures: } \\
\hline Body mass index $\left[\mathrm{kg} / \mathrm{m}^{2}\right]$ & 25.5 & 29.02 & 0.04 \\
\hline Overweight, $n$ (\%) & $129(75.6)$ & $23(79.0)$ & 0.29 \\
\hline Arterial hypertension, $n(\%)$ & $126(74.0)$ & $24(84.2)$ & 0.05 \\
\hline Current smoking, $n(\%)$ & $123(71.8)$ & $18(63.2)$ & 0.22 \\
\hline Family history of IHD, $n$ (\%) & $41(23.7)$ & $20(68.4)$ & 0.03 \\
\hline Family history of T2DM, $n(\%)$ & $5(2.9)$ & $7(24.1)$ & 0.01 \\
\hline $\begin{array}{l}\text { Clinic angina to myocardial } \\
\text { infarction, } n(\%)\end{array}$ & $91(53.0)$ & $15(52.6)$ & 0.32 \\
\hline Previous myocardial infarction, $n(\%)$ & $47(27.6)$ & $12(42.1)$ & 0.12 \\
\hline $\begin{array}{l}\text { Cerebrovascular accident/transient } \\
\text { ischemic attack in history, } n(\%)\end{array}$ & $9(5.5)$ & $2(5.2)$ & 0.36 \\
\hline A history of heart failure, $n(\%)$ & $60(35.4)$ & $6(21.0)$ & 0.37 \\
\hline \multicolumn{4}{|l|}{ Depth of lesion: } \\
\hline Q-wave MI & $119(69.6)$ & $24(84.2)$ & 0.04 \\
\hline Non-Q-wave MI & $52(30.4)$ & $5(15.8)$ & 0.05 \\
\hline \multicolumn{4}{|l|}{ Localization of MI: } \\
\hline Posterior & $62(35.61)$ & $12(42.1)$ & 0.12 \\
\hline $\begin{array}{l}\text { Posterior taking the right ventricle } \\
\text { front }\end{array}$ & $11(6.50)$ & $2(5.2)$ & 0.36 \\
\hline Front & $98(55.8)$ & $15(52.6)$ & 0.12 \\
\hline \multicolumn{4}{|l|}{ Acute heart failure (Killip): } \\
\hline I & $143(83.9)$ & $17(57.9)$ & 0.043 \\
\hline II & $18(10.4)$ & $7(26.3)$ & 0.036 \\
\hline III & $7(3.3)$ & $5(15.8)$ & 0.022 \\
\hline IV & $3(2.2)$ & 0 & \\
\hline Rhythm disturbance, $n$ (\%) & $86(50.2)$ & $15(52.6)$ & 0.231 \\
\hline Early post-infarction angina, $n(\%)$ & $10(6.1)$ & $7(26.3)$ & 0.023 \\
\hline $\begin{array}{l}\text { Recurrent MI (for the period of stay in } \\
\text { hospital), } n(\%)\end{array}$ & $7(4.4)$ & $5(15.8)$ & 0.031 \\
\hline
\end{tabular}




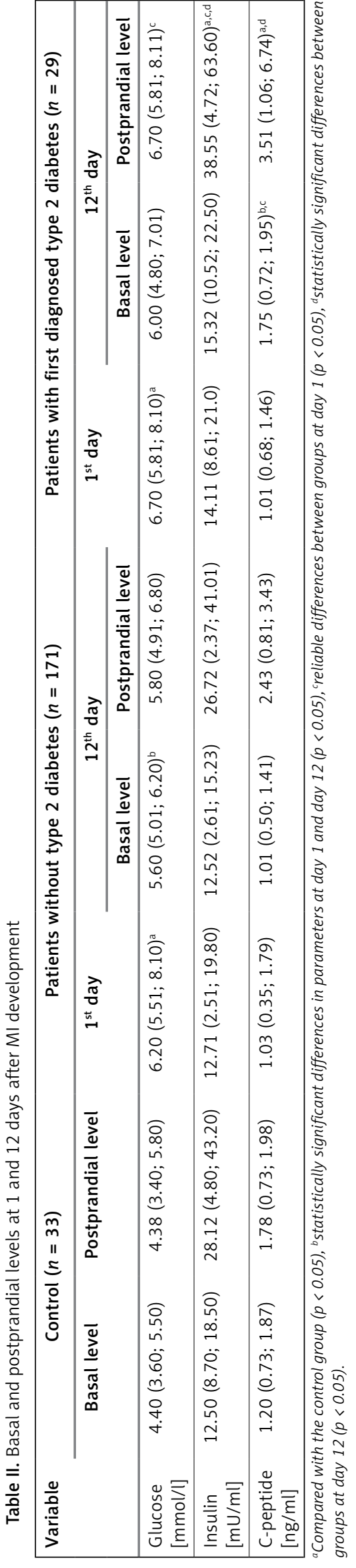

time points using a standard Thermo Fisher Scientific test system (Thermo Fisher Scientific Oy, Vantaa, Finland) in a Konelab 30i biochemistry analyzer (Thermo Fisher Scientific Oy).

The intra-assay coefficients of variation (CV) for insulin Diagnostic Systems Laboratories and C-peptide ELISA were 3.8 and $4.2 \%$, respectively, and the inter-assay CV were 6.9 and $7.9 \%$, respectively.

Adipokines (leptin, adiponectin, resistin and retinol-binding protein (RBP)) and ghrelin levels were measured with the BioVendor R\&D Product (Brno, Czech Republic) and intra-assay CV values were 5.9 and $6.8 \%$. Proinflammatory factors (interleukin-6 (IL-6) and tumor necrosis factor $\alpha$ (TNF- $\alpha$ )) were assessed using standard test kits (Bender MedSystems GmbH, Vienna, Austria) (CV, 7.03-8.99\%), C-reactive protein (CRP) (Biomerica, Irvine, CA, USA) (CV, 2.3-4.1\%) and plasminogen activator inhibitor (PAl-1) (Technoclone GmbH, Vienna, Austria) (CV, 4.03-6.39\%).

\section{Statistical analysis}

Statistical analysis was performed using Statistica 6.1. software (InstallShield Software Corp., Chicago, IL, USA) and SPSS 10.0 for Windows (SPSS Inc., Chicago, IL, USA). Results are presented as median (Me) and 25 and $75 \%$ quartiles $\mathrm{Me}$ (Q1; Q3). Nonparametric tests were used to assess and analyze data. The Mann-Whitney $U$ test or the Kolmogorov-Smirnov method (more than 50 cases in each group) were used for quantitative comparisons of two independent groups. The Spearman rank correlation coefficient was used to investigate relationships between variables. Stepwise logistic regression analysis with odds ratios (OR) and $95 \%$ confidence intervals $(\mathrm{Cl})$ were used to determine the prognostic significance of parameters in long-term prognosis. Cox regression was used to evaluate the risk of unfavorable events; the impact of independent variables, predictors of risk, was determined. A $p$-value of $<0.05$ was considered statistically significant.

\section{Results}

One year after MI, type 2 diabetes was verified in $29(14.5 \%)$ patients. Five patients were diagnosed with the disease after 7 months following a visit to the endocrinologist, 18 patients were diagnosed after 9 months after MI during routine clinical examinations, and 6 patients were diagnosed during a follow-up visit to the center after 12 months.

The OGTT defined impaired carbohydrate tolerance in patients with newly diagnosed type 2 diabetes in acute MI (Table II). There was a 1.6fold increase of postprandial glucose levels, a 1.4fold increase of insulin and a 1.9-fold increase of 
C-peptide compared with healthy control subjects, and a 1.2-fold, 1.4-fold and 1.7-fold increase, respectively, compared with non-diabetic patients.

The manifestation of diabetes in examined patients was associated with the progression of impaired insulin resistance, diagnosed during the in-hospital period of MI. Analysis of insulin resistance using QUICKI estimated in the acute phase of MI showed significant differences between the diabetic and non-diabetic patients. The QUICKI was $0.293 \pm 0.012$ in patients with newly diagnosed diabetes, and corresponded to remarkable tissue-specific insulin resistance. One year later the QUICKI decreased to $0.280 \pm 0.014(p=0.004)$. In patients without diabetes, the QUICKI corresponded to moderate insulin resistance, both in the acute phase and 1 year after MI. For both groups of patients the QUICKI values were lower than that observed for the control group $(0.380 \pm 0.010)$.

The development of diabetes in the post-hospital period was facilitated by cardiovascular risk factors and a history of diabetes in patients with MI. All patients with diabetes, verified 1 year after MI, were overweight and hypertensive and had a genetic burden for coronary heart disease and diabetes.
Initiation of diabetes over the longer term was preceded by a more severe course of the disease during the in-hospital period; Q-wave MI prevailed in diabetic patients as well as signs of congestive heart failure Killip class II-IV. Common in-hospital complications of $\mathrm{MI}$ included early post-infarction angina and recurrent $\mathrm{MI}$ (Table III).

The post-hospital period of $\mathrm{MI}$ in patients with diabetes was also defined by a more severe course. Diabetic patients with $\mathrm{Ml}$ had a higher incidence of unstable angina, reinfarction and decompensated heart failure, requiring hospitalization (Table III). There were therefore no differences in therapies during the post-hospital period. All patients received antiplatelet $(95 \%$ and $80.9 \%$, $p=0.23)$, coronaroactive ( $98 \%$ and $96 \%, p=0.46)$ and hypolipidemic ( $89 \%$ and $75 \%, p=0.75)$ therapies at almost the same frequency.

Logistic regression analysis allowed for the identification of factors associated with the manifestation of diabetes within 1 year after MI (Table IV). The most statistically significant parameters were severity of congestive heart failure and infarct size (Table V). In all derived anthropometric indices, an increased body mass index (BMI) had a close relationship with diabetes development. Howev-

Table III. Adverse outcomes observed in MI patients with and without diabetes at 1 year after MI

\begin{tabular}{|lccc|}
\hline Endpoints & $\begin{array}{c}\text { Patients without } \\
\text { type 2 diabetes }(n=171)\end{array}$ & $\begin{array}{c}\text { Patients with first diagnosed } \\
\text { type 2 diabetes }(n=29)\end{array}$ & $P$-value \\
\hline Unstable angina & $31(18.1 \%)$ & $9(31 \%)$ & 0.008 \\
\hline Reinfarction & $19(11 \%)$ & $6(21 \%)$ & 0.003 \\
\hline Decompensation of chronic heart failure & $35(20.46 \%)$ & $11(37.93 \%)$ & 0.002 \\
\hline
\end{tabular}

P-value for differences between groups.

Table IV. Biochemical maker data for the development of diabetes at 1 year after MI

\begin{tabular}{|c|c|c|c|c|c|c|c|c|}
\hline \multirow[t]{2}{*}{ Variable } & \multicolumn{4}{|c|}{$1^{\text {st }}$ day } & \multicolumn{4}{|c|}{$12^{\text {th }}$ day } \\
\hline & OR & $95 \% \mathrm{Cl}$ & AUN & $P$-value & OR & $95 \% \mathrm{Cl}$ & AUN & $P$-value \\
\hline Glucose $[\mathrm{mmol} / \mathrm{l}]$ & 1.07 & $1.05-1.95$ & 0.62 & 0.01 & 2.99 & $1.77-5.95$ & 0.87 & 0.03 \\
\hline Insulin [mU/ml] & 1.08 & $1.01-1.17$ & 0.74 & 0.04 & 2.99 & $1.01-1.47$ & 0.83 & 0.04 \\
\hline C-peptide [ng/ml] & 1.98 & $1.03-1.22$ & 0.58 & 0.33 & 1.52 & $1.08-1.07$ & 0.79 & 0.02 \\
\hline $\mathrm{TC}[\mathrm{mmol} / \mathrm{l}]$ & 1.14 & $1.01-1.02$ & 0.51 & 0.41 & 0.93 & 0.99-1.05 & 0.47 & 0.64 \\
\hline TAG [mmol/l] & 1.82 & $0.77-1.89$ & 0.65 & $<0.001$ & 1.22 & $1.11-1.35$ & 0.58 & 0.04 \\
\hline $\mathrm{HDL}-\mathrm{C}[\mathrm{mmol} / \mathrm{l}]$ & 0.87 & $0.98-1.04$ & 0.42 & 0.86 & 0.42 & $0.99-1.00$ & 0.48 & 0.22 \\
\hline LDL-C [mmol/l] & 0.99 & $0.47-3.60$ & 0.47 & 0.96 & 0.51 & $0.80-1.23$ & 0.34 & 0.02 \\
\hline VLDL-C [mmol/l] & 3.74 & $0.59-1.64$ & 0.65 & $<0.001$ & 2.18 & $1.09-1.51$ & 0.58 & 0.04 \\
\hline аро B [g/l] & 1.20 & $0.17-4.40$ & 0.61 & 0.43 & 0.82 & $0.61-1.60$ & 0.52 & 0.54 \\
\hline apo A1 [g/l] & 1.05 & $0.96-1.04$ & 0.48 & 0.96 & 0.80 & $0.83-1.57$ & 0.49 & 0.60 \\
\hline apo B/apo A1 & 0.98 & $1.52-9.21$ & 0.65 & 0.90 & 1.83 & $0.17-6.49$ & 0.51 & 0.06 \\
\hline
\end{tabular}

$P$-value compared with the control group. TC - total cholesterol, TAG - triglyceride, HDL-C - high-density lipoprotein cholesterol, LDL-C - low-density lipoprotein cholesterol, VLDL-C - very-low-density lipoprotein cholesterol, apo B - apolipoprotein B, apo A1 apolipoprotein $A 1$. 
Table V. Clinical data of the development of diabetes at 1 year after MI

\begin{tabular}{|c|c|c|c|c|}
\hline Variable & OR & $95 \% \mathrm{Cl}$ & AUC & $P$-value \\
\hline Age [years] & 0.99 & $0.74-3.57$ & 0.46 & 0.77 \\
\hline Killip & 1.63 & $1.01-1.81$ & 0.53 & 0.02 \\
\hline Number of affected arteries & 1.38 & $0.91-3.67$ & 0.59 & 0.18 \\
\hline Ejection fraction & 1.01 & $0.99-1.14$ & 0.52 & 0.81 \\
\hline Body mass index & 1.10 & $1.21-2.74$ & 0.61 & 0.03 \\
\hline Myocardial infarct size & 1.2 & $1.04-2.1$ & 0.5 & 0.02 \\
\hline Percutaneous coronary intervention & 0.26 & $0.1-0.9$ & 0.75 & 0.04 \\
\hline Insulin resistance & 4.17 & $1.12-15.58$ & 0.91 & 0.03 \\
\hline
\end{tabular}

$P$-value compared with the control group. OR - odds ratio, $95 \% \mathrm{Cl}-95 \%$ confidence interval, $A U C$ - area under the ROC curve.

er, the presence of insulin resistance during the in-hospital period significantly contributed to the manifestation of diabetes and resulted in a 4-fold increased risk for developing type 2 diabetes 1 year after MI (Table V).

The most informative markers of diabetes among carbohydrate metabolism parameters were glucose, insulin and C-peptide, measured on day 12 of MI. Elevated levels of glucose and insulin provoked a 3-fold increase of insulin resistance risk and a 1.5-fold increase of C-peptide.

Besides carbohydrate metabolism disorders, lipid metabolism disorders were detected. Patients with newly diagnosed diabetes reported elevated levels of TAG, VLDL-C, and apo B/apo A ratio and low levels of HDLC compared with nondiabetic patients and the control group (Table VI). The greatest changes were observed in FFA levels, with diabetic patients showing a 9-fold increase in FFA and patients without diabetes showing a 8.2- fold increase on day 1 compared with the control group (Table $\mathrm{VI}$ ). By day 12, patients in both groups showed decreased FFA levels, but levels remained 3.5-fold higher than the control group.

For parameters of lipid metabolism, FFA levels were independently associated with insulin resistance development in MI. Elevated FFA levels on day 1 at $1 \mathrm{mmol} / \mathrm{l}$ increased 1.8-fold the risk of insulin resistance development, and on day 12 increased 2-fold. While increased TAG and VLDL-C levels had statistically significant associations with the manifestation of diabetes, they did not have high diagnostic specificity or sensitivity; the area under the curve (AUC) was 0.65 , corresponding to an unsatisfactory quality of the model (Table IV).

Assessment of adipokine status showed a reduction of ghrelin as well as low activation of proinflammatory and thrombotic potentials of blood plasma. A 2.05-fold increase in leptin lev-

Table VI. Lipid profiles for patients with MI in the dynamics of hospital stay (Me: Q1; Q3)

\begin{tabular}{|c|c|c|c|c|c|}
\hline \multirow[t]{2}{*}{ Variable } & \multirow[t]{2}{*}{ Control $(n=33)$} & \multicolumn{2}{|c|}{$\begin{array}{c}\text { Patients without } \\
\text { type } 2 \text { diabetes }(n=171)\end{array}$} & \multicolumn{2}{|c|}{$\begin{array}{l}\text { Patients with first diagnosed } \\
\text { type } 2 \text { diabetes }(n=29)\end{array}$} \\
\hline & & $1^{\text {st }}$ day & $12^{\text {th }}$ day & $1^{\text {st }}$ day & $12^{\text {th }}$ day \\
\hline $\mathrm{TC}[\mathrm{mmol} / \mathrm{l}]$ & $4.30(3.50 ; 6.10)$ & $5.55(4.40 ; 6.50)^{\mathrm{a}}$ & $5.40(4.40 ; 6.40)$ & $5.50(4.20 ; 7.00)^{a}$ & $5.70(4.90 ; 6.10)$ \\
\hline TAG [mmol/l] & $1.13(0.78 ; 1.23)$ & $1.60(1.15 ; 2.17)$ & $2.05(1.43 ; 2.70)^{b}$ & $2.75(2.01 ; 2.87)^{\mathrm{a}, \mathrm{c}}$ & $2.57(1.44 ; 3.22)$ \\
\hline $\mathrm{HDL}-\mathrm{C}[\mathrm{mmol} / \mathrm{l}]$ & $1.31(1.02 ; 1.72)$ & $1.02(0.83 ; 1.16)$ & $1.02(0.84 ; 1.16)$ & $0.78(0.58 ; 0.94)^{a, c}$ & $0.84(0.58 ; 1.13)$ \\
\hline LDL-C [mmol/ll] & $2.03(1.51 ; 2.55)$ & $2.74(2.09 ; 3.41)$ & $2.62(1.95 ; 3.35)$ & $1.98(1.86 ; 3.10)$ & $2.41(0.82 ; 2.56)$ \\
\hline VLDL-C [mmol/ll] & $0.44(0.33 ; 0.53)$ & $0.73(0.52 ; 0.98)$ & $0.93(0.65 ; 1.23)^{b}$ & $1.25(0.91 ; 1.30)^{\mathrm{a}, \mathrm{c}}$ & $1.17(0.65 ; 1.46)$ \\
\hline apo B [g/l] & $1.02(0.76 ; 1.25)$ & $1.18(0.95 ; 1.39)$ & $1.36(1.08 ; 1.64)^{b}$ & $1.51(1.19 ; 1.72)^{\mathrm{a}}$ & $1.38(1.21 ; 1.84)$ \\
\hline apo A1 [g/l] & $1.43(1.29 ; 1.73)$ & $1.27(1.11 ; 1.42)$ & $1.38(1.18 ; 1.74)^{\mathrm{b}}$ & $1.13(1.06 ; 1.22)^{\mathrm{a}}$ & $1.15(1.01 ; 1.63)$ \\
\hline apo B/apo A1 & $0.71(0.59 ; 1.00)$ & $0.90(0.75 ; 1.12)$ & $0.92(0.73 ; 1.16)$ & $1.25(1.12 ; 1.62)^{\mathrm{a}, \mathrm{c}}$ & $1.05(0.83 ; 1.60)$ \\
\hline $\mathrm{FFA}[\mu \mathrm{mol} / \mathrm{l}]$ & $0.20(0.10 ; 1.10)$ & $1.63(1.24 ; 2.00)^{\mathrm{a}}$ & $0.54(0.41 ; 0.73)^{b}$ & $1.91(1.62 ; 2.05)^{a}$ & $0.90(0.59 ; 0.99)^{b, c}$ \\
\hline
\end{tabular}


els, a 4.56-fold increase in RBP and an 8.15-fold increase in FFA levels were determined on day 1 of $\mathrm{MI}$, whereas the antidiabetic protective factor ghrelin decreased 3.24-fold compared with the control group (Table VII). IL-6, CRP, TNF- $\alpha$ and PAI- 1 increased at 3.78-, 22.96-, 11.66- and 2.43-fold, respectively, compared with the control group.

Patients with verified diabetes 1 year after $\mathrm{Ml}$ showed more pronounced changes in the studied parameters during the in-hospital period. On day 1 of $\mathrm{MI}$, the levels of diabetes-related adipokines (leptin, resistin, RBP) and FFA were 1.83-, 1.92-, 1.38- and 1.17-fold higher compared with non-diabetic patients (Table VII). Ghrelin and adiponectin levels in patients with diabetes decreased 1.4- and 4-fold compared with the control group, and 1.18- and 1.23-fold compared with diabetic patients. Concentrations of IL-6, TNF- $\alpha$ and PAI- 1 increased 1.7-fold compared with non-diabetic patients (Table VII).

On day 12 of $\mathrm{MI}$, patients without diabetes showed a 1.4-fold decrease in leptin, a 1.17-fold decrease in RBP and a 3-fold decrease in FFA. Resistin and adiponectin levels were within the range of the control group, but ghrelin deficiency remained (Table VII).

A similar pattern was observed for proinflammatory and prothrombogenic factors: levels of IL-6 decreased 1.9-fold, CRP decreased 2.2-fold, and PAI-1 decreased 1.37-fold compared with day 1 .
The exception was TNF- $\alpha$ levels, which increased by $41 \%$.

Patients with diabetes manifestation had pronounced changes on day 12 of the hospital stay. Leptin, resistin, RBP and FFA showed 1.8-, 1.4-, 1.3- and 1.6-fold increases, respectively, compared with patients without diabetes (Table VII). The concentrations of adiponectin and ghrelin decreased 1.35- and 1.31-fold compared with non-diabetic patients.

Levels of proinflammatory factors (IL-6 and (RP) on day 12 decreased 2.3- and 1.8-fold compared with day 1 , but remained 1.4- and 2.1-fold higher than levels in patients without diabetes. There was no essential dynamics of PAI- 1 . The TNF- $\alpha$ levels increased $32 \%$ and exceeded 1.65fold the values of the non-diabetic group.

Although adipokines (resistin and leptin) and the proinflammatory factor CRP showed statistically significant differences, these markers did not show high diagnostic sensitivity or specificity, which represented an AUC value equal to 0.6, corresponding to a low quality of the model (Table VIII).

From AUC $>0.75$ values, the most sensitive and specific markers were adiponectin, ghrelin, RBP, TNF- $\alpha$, IL- 6 and PAI-1. Low levels of adiponectin during the in-hospital period of $\mathrm{MI}$ increased the risk for developing diabetes by $50 \%$ and ghrelin increased the risk by $78-81 \%$ (Table VIII). Elevated levels of TNF- $\alpha$, IL-6, RBP and PAI-1 increased 1.5-,

Table VII. Adipokine, prothrombogenic and proinflammatory levels in patients at 1 and 12 days after MI (Me: Q1; Q3)

\begin{tabular}{|c|c|c|c|c|c|}
\hline \multirow[t]{2}{*}{ Variable } & \multirow[t]{2}{*}{$\begin{array}{l}\text { Control } \\
(n=33)\end{array}$} & \multicolumn{2}{|c|}{$\begin{array}{c}\text { Patients without } \\
\text { type } 2 \text { diabetes }(n=171)\end{array}$} & \multicolumn{2}{|c|}{$\begin{array}{l}\text { Patients with first diagnosed } \\
\text { type } 2 \text { diabetes }(n=29)\end{array}$} \\
\hline & & $1^{\text {st }}$ day & $12^{\text {th }}$ day & $1^{\text {st }}$ day & $12^{\text {th }}$ day \\
\hline $\begin{array}{l}\text { Leptin } \\
{[\mathrm{ng} / \mathrm{ml}]}\end{array}$ & $\begin{array}{c}6.98 \\
(4.5 ; 9.75)\end{array}$ & $\begin{array}{c}14.34 \\
(9.54 ; 27.67)^{a}\end{array}$ & $\begin{array}{c}10.13 \\
(8.43 ; 22.80)^{b}\end{array}$ & $\begin{array}{c}26.29 \\
(20.45 ; 29.31)^{\mathrm{a}, \mathrm{c}}\end{array}$ & $\begin{array}{c}18.69 \\
(14.86 ; 27.30)^{\mathrm{b}, \mathrm{d}}\end{array}$ \\
\hline $\begin{array}{l}\text { Resistin } \\
{[\mathrm{ng} / \mathrm{ml}]}\end{array}$ & $\begin{array}{c}7.0 \\
(3.8 ; 9.8)\end{array}$ & $\begin{array}{c}8.67 \\
(4.60 ; 10.78)\end{array}$ & $\begin{array}{c}8.60 \\
(4.60 ; 10.50)\end{array}$ & $\begin{array}{c}16.66 \\
(9.98 ; 18.22)^{a, c}\end{array}$ & $\begin{array}{c}11.76 \\
(9.89 ; 17.38)^{\mathrm{a}, \mathrm{b}, \mathrm{d}}\end{array}$ \\
\hline $\begin{array}{l}\text { Retinol-binding } \\
\text { protein }[\mu \mathrm{g} / \mathrm{ml}]\end{array}$ & $\begin{array}{c}47.5 \\
(20.0 ; 76.7)\end{array}$ & $\begin{array}{c}216.95 \\
(185.20 ; 246.25)^{a}\end{array}$ & $\begin{array}{c}185.88 \\
(194.23 ; 248.75)^{a, b}\end{array}$ & $\begin{array}{c}299.85 \\
(212.60 ; 278.90)^{a, c}\end{array}$ & $\begin{array}{c}243.35 \\
(184.20 ; 245.10)^{a, b, d}\end{array}$ \\
\hline $\begin{array}{l}\text { Adiponectin } \\
{[\mathrm{mg} / \mathrm{ml}]}\end{array}$ & $\begin{array}{c}11.35 \\
(7.3 ; 13.5)\end{array}$ & $\begin{array}{c}11.20 \\
(9.00 ; 15.20)\end{array}$ & $\begin{array}{c}11.45 \\
(8.63 ; 15.00)\end{array}$ & $\begin{array}{c}8.10 \\
(6.50 ; 8.50)^{a, c}\end{array}$ & $\begin{array}{c}8.50 \\
(7.90 ; 13.80)^{a, c}\end{array}$ \\
\hline Ghrelin [ng/ml] & $\begin{array}{c}55.2 \\
(31.6 ; 90.2) \\
\end{array}$ & $\begin{array}{c}17.06 \\
(14.80 ; 17.67)^{a}\end{array}$ & $\begin{array}{c}16.86 \\
(13.12 ; 18.20)^{\mathrm{a}}\end{array}$ & $\begin{array}{c}13.81 \\
(11.21 ; 18.27)^{\mathrm{a}, \mathrm{c}}\end{array}$ & $\begin{array}{c}12.86 \\
(11.12 ; 18.20)^{a, d}\end{array}$ \\
\hline $\begin{array}{l}\text { Interleukin-6 } \\
{[\mathrm{pg} / \mathrm{ml}]}\end{array}$ & $\begin{array}{c}3.90 \\
(2.80 ; 4.10)\end{array}$ & $\begin{array}{c}14.78 \\
(9.02 ; 21.64)^{\mathrm{a}}\end{array}$ & $\begin{array}{c}7.76 \\
(2.7 ; 12.19)^{\mathrm{b}}\end{array}$ & $\begin{array}{c}25.92 \\
(14.45 ; 38.03)^{\mathrm{a}, \mathrm{c}}\end{array}$ & $\begin{array}{c}11.24 \\
(9.36 ; 14.94)^{b, d}\end{array}$ \\
\hline $\begin{array}{l}\text { C-reactive } \\
\text { protein }[\mathrm{mg} / \mathrm{l}]\end{array}$ & $\begin{array}{c}1.15 \\
(0.86 ; 2.10)\end{array}$ & $\begin{array}{c}26.41 \\
(14.00 ; 40.80)^{\mathrm{a}}\end{array}$ & $\begin{array}{c}11.87 \\
(5.00 ; 20.47)^{\mathrm{b}}\end{array}$ & $\begin{array}{c}45.00 \\
(15.97 ; 60.00)^{a, c}\end{array}$ & $\begin{array}{c}25.0 \\
(6.00 ; 37.21)^{\mathrm{b}, \mathrm{d}}\end{array}$ \\
\hline $\begin{array}{l}\text { Tumor necrosis } \\
\text { factor- } \alpha[\mathrm{pg} / \mathrm{ml}]\end{array}$ & $\begin{array}{c}1.20 \\
(0.90 ; 2.10)\end{array}$ & $\begin{array}{c}14.00 \\
(12.87 ; 22.86)^{\mathrm{a}}\end{array}$ & $\begin{array}{c}19.80 \\
(11.84 ; 23.25)^{\mathrm{b}}\end{array}$ & $\begin{array}{c}24.80 \\
(21.64 ; 23.50)^{\mathrm{a}, \mathrm{c}}\end{array}$ & $\begin{array}{c}32.76 \\
(21.56 ; 44.57)^{\mathrm{b}, \mathrm{d}}\end{array}$ \\
\hline $\begin{array}{l}\text { Plasminogen } \\
\text { activator } \\
\text { inhibitor-1 } \\
{[\mathrm{ng} / \mathrm{ml}]}\end{array}$ & $\begin{array}{c}35.25 \\
(28.30 ; 46.30)\end{array}$ & $\begin{array}{c}85.80 \\
(37.24 ; 131.00)^{a}\end{array}$ & $\begin{array}{c}62.34 \\
(37.24 ; 102.10)^{b}\end{array}$ & $\begin{array}{c}143.70 \\
(137.00 ; 183.10)^{\mathrm{a}, \mathrm{c}}\end{array}$ & $\begin{array}{c}145.30 \\
(85.79 ; 202.50)^{d}\end{array}$ \\
\hline
\end{tabular}




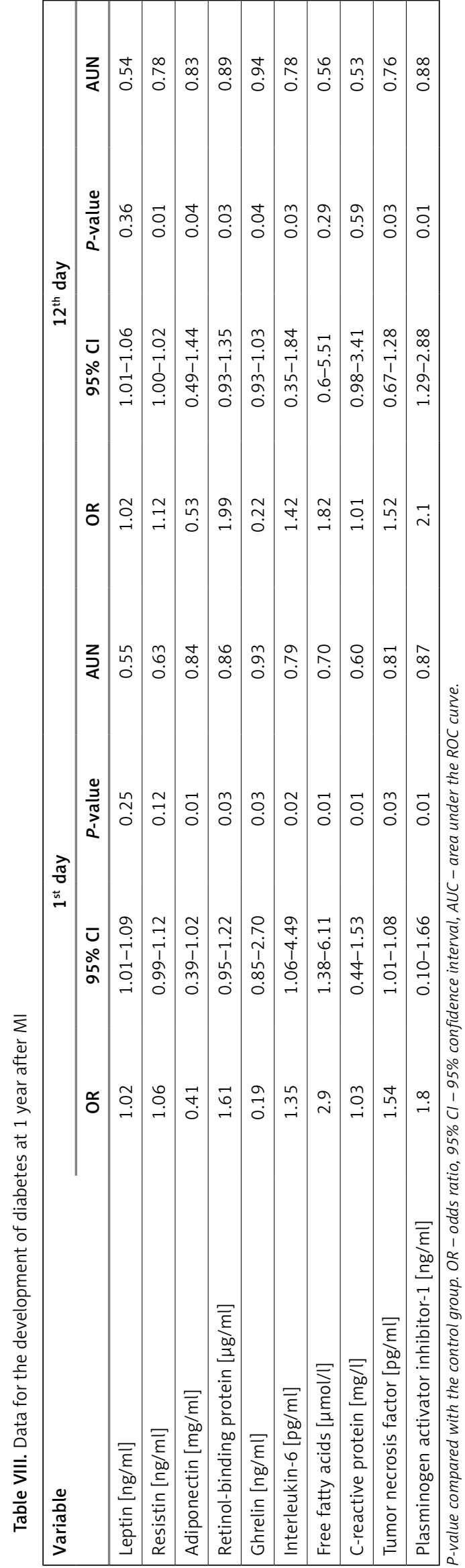

1.4-, 1.8- and 2-fold the risk for developing diabetes (Table VIII).

\section{Discussion}

Acute coronary syndrome is commonly associated with a high incidence of in-hospital and post-hospital complications. On average, 19-23\% of patients with acute MI suffer from type 2 diabetes [13]. Impaired glucose tolerance is observed in a significant number of patients. This category of patients is at high risk for developing cardiovascular diseases $[13,14]$ and diabetes.

The results of the current study showed that $14.5 \%$ of patients at 1 year after MI suffered from type 2 diabetes. The in-hospital period of MI for these patients was characterized by severe insulin resistance. Insulin resistance transformation into diabetes in the current study may have been provoked by several pathological factors during the acute phase, these being basal and postprandial hyperglycemia, hyperinsulinemia, dyslipidemia, adipokine imbalance and activation of proinflammatory and prothrombogenic potentials. One year after MI, insulin resistance was aggravated and reached diagnostic values for diabetes and was associated with a high incidence of adverse cardiovascular events, including recurrent MI, progressive angina and decompensated heart failure.

Late diabetes manifestation was preceded by a more severe hospital period of infarction, including heart failure, recurrent ischemia and myocardial contractile dysfunction. Results from the current study are consistent with a study by Stubbs et al. [15]. In that study, the authors reported that insulin resistance was a reliable predictor of adverse cardiovascular events over the long term in patients with $\mathrm{Ml}$ and without a history of diabetes. This predictive ability of insulin resistance remained after adjustments were made for gender, age and BMI. Of note, the authors did not find a similar pattern for patients with stable coronary artery disease.

An important factor for the manifestation of diabetes in the late MI period may be the presence of cardiovascular risk factors, including obesity, hypertension and genetic burden for diabetes, with insulin resistance being a common pathogenic link [16]. From regression analysis in the current study, the presence of insulin resistance during the in-hospital period of MI was associated with a 4-fold increased risk for developing type 2 diabetes 1 year after $\mathrm{MI}(\mathrm{OR}=4.17 ; 95 \% \mathrm{Cl}$ : 1.12-15.58). This finding is consistent with the concept of the triggering role of carbon exchange in diabetes manifestation.

The results of the current suggest that insulin resistance may not only be a response to catecholamine stress accompanying $\mathrm{MI}$, but also 
a pathophysiological basis for metabolic and neuro-endocrine disorders contributing to adverse long-term outcomes in ACS. Insulin is known to stimulate intracellular transport of glucose, which is the preferable substrate for cardiomyocytes in ischemia/reperfusion injury. Experimental studies reported a decrease of glycogen synthesis in cardiomyocytes in insulin resistance due to impaired glucose transport into cells [17]. Recently, cardiomyocytes in patients with coronary artery disease demonstrated the same resistance to insulin, mediating glucose distribution towards glycolysis [17]. Activation of glycolysis in ischemic myocardium can be counterproductive because of the accumulation of reactive oxygen species and lactate with cytotoxic effects. Therefore, MI patients with insulin resistance may be affected not only by low glycogen in cardiomyocytes, but also further delivery of glucose to ischemic cardiomyocytes will contribute to a reduction, resulting in a cell energy deficit and subsequent decrease in functional activity.

In the current study, the in-hospital course of $\mathrm{MI}$ in patients with manifested diabetes was accompanied by the highest levels of blood FFA. Nolan et al. [18] suggested that under physiological conditions FFA can stimulate insulin secretion from its own receptor (FFAR1/GPR40) on $\beta$-cells as well as by intermediate metabolites (LC-CoA, $\mathrm{DAG}, \mathrm{PL}$ ) involved in the signaling pathways, regulating insulin secretion. However, chronic excess of FFA, apparently caused by induction of lipolysis in adipocytes and impaired FFA utilization by cardiomyocytes in myocardial ischemia with hyperglycemia, reduces biosynthesis [19] and insulin secretion [20] and induces apoptosis of $\beta$-cells [21].

Pathological activation of FFA is known to be limited by adiponectin, which blocks the synthesis of FFA and enhances FFA oxidation and increases sensitivity to insulin [22]. Decreased levels of adiponectin in the acute phase of MI may contribute to FFA lipotoxic effects, insulin resistance development and diabetes manifestation over the longer term of the disease.

The RBP had a more pronounced prognostic value compared with adiponectin, showing 1.6and 1.99-fold increases for the risk for developing diabetes. The high diagnostic value of RBP is associated with its ability to induce enzymes of gluconeogenesis and, as a consequence, hyperglycemia. Additionally, RBP decreases insulin-stimulated glucose uptake by myocytes, inhibits the functioning of the GLUT-4 glucose transporter and inhibits insulin secretion by pancreatic $\beta$-cells $[22$, 23]. It is possible that leptin may contribute to increased RBP expression as its level increased 1.8fold in patients with diabetes in the current study. Mattu and Randeva suggested leptin to have a dose-dependent effect in relation to the stimulation of the expression of RBP in adipocytes [10].

Patients with manifested diabetes 1 year after $\mathrm{Ml}$ demonstrated more pronounced signs of nonspecific inflammation (elevated levels of IL-6, TNF- $\alpha$ and (RP) in the acute phase of the disease. Increases in concentrations of proinflammatory factors were accompanied by hyperglycemia and hyperinsulinemia, elevated levels of FFA and adipokines initiating insulin resistance, and deficit of the antidiabetogenic factors adiponectin and ghrelin.

In terms of physiological norms, interactions between adipokines that induce and block insulin resistance development are coordinated by proinflammatory cytokines, which also have the ability to modulate intracellular signaling of insulin [6]. Proinflammatory factors are known to induce the expression of adipokine mRNA in cardiomyocytes and adipocytes [6]. Thus, adipokines affect the synthesis of TNF- $\alpha$ and IL- 6 by immune system cells [5]. The acute phase of $\mathrm{Ml}$ is marked by excess expression of proinflammatory factors in the ischemic/myocardial necrotic zone and secretion into the blood, having a significant impact on adipokine imbalance. With a predominance of adipokines, tissue sensitivity to insulin is affected and contributes to hyperglycemia and diabetes within 1 year.

The association between the activation of inflammation and thrombosis, the underlying cause of atherosclerosis, and, particularly, acute MI, is established [19]. Most cases of coronary thrombosis occur as a result of destabilization of atherosclerotic plaques and are followed by release of proinflammatory cytokines into the systemic circulation, triggering a cascade of events leading to inflammation, endothelial injury and vascular thrombosis [24]. Proinflammatory cytokines activate the generation of proteins, depressing the fibrinolysis system, particularly PAI-1 [25]. In the current study, increased levels of PAI-1 were observed in both groups of patients; patients with newly diagnosed type 2 diabetes 1 year after $\mathrm{MI}$ showed high levels during the in-hospital period.

Correlations were observed between the concentrations of PAI- 1 and IL- $6(r=0.51, p=0.002)$, and TNF- $\alpha(r=0.47, p=0.001)$ in MI patients. This supports our hypothesis, which suggests the involvement of thrombus cytokine-associated mechanisms.

Elevated PAI-1 levels may also be caused by ghrelin deficiency, which showed low concentrations especially in patients with verified diabetes 1 year after MI. It has previously been reported that PAI-1 levels negatively correlated with ghrelin levels in children with a simple type of obesity [26]. The authors suggested that suppression of ghrelin secretion may be provoked by higher insulin resistance and may be associated with visceral fat 
accumulation and elevated levels of PAI-1 [27]. In the current study, ghrelin was characterized by a high predictive value in relation to the development of diabetes on days 1 and 12 of MI. Ghrelin improves insulin sensitivity by activating AMP-kinase and neutralizing FFA cytotoxic effects and their metabolic intermediates.

In conclusion, adiponectin, RBP, ghrelin, TNF- $\alpha$ and PAI-1 appear to be the most informative biochemical parameters associated with the development of diabetes 1 year after MI. Accumulation of prothrombogenic and proinflammatory proteins, adipokines, in the peripheral circulation affects tissue sensitivity to insulin, contributing to malfunctioning of cardiomyocytes and worsened myocardial contractile function and triggering the clinical manifestations of insulin resistance in diabetes.

\section{Acknowledgments}

The authors wish to thank Olga Akbasheva for assistance in writing this article.

\section{Conflict of interest}

The authors declare no conflict of interest.

\section{References}

1. Hansson GK. Inflammation, atherosclerosis, and coronary artery disease. N Engl J Med 2005; 352: 1685-95.

2. Karetnikova VN, Gruzdeva OV, Barbarash OL. The role of markers of inflammation in assessment of prognosis in patients with ST-elevation myocardial infarction combined with disturbances of carbohydrate metabolism. Kardiologiia 2012; 52: 20-6.

3. Rydén L, Grant PJ, Anker SD, et al. ESC Guidelines on diabetes, pre-diabetes, and cardiovascular diseases developed in collaboration with the EASD: the Task Force on diabetes, pre-diabetes, and cardiovascular diseases of the European Society of Cardiology (ESC) and developed in collaboration with the European Association for the Study of Diabetes (EASD). Eur Heart J 2013; 39: 3035-87.

4. Deedwania P, Kosiborod M, Barrett E, et al. Hyperglycemia and acute coronary syndrome: a scientific statement from the American Heart Association Diabetes Committee of the Council on Nutrition, Physical Activity, and Metabolism. Anesthesiology 2008; 109: 14-24.

5. Shesternja PA, Shulman VA, Nikulin SY. Genetic aspects of myocardial infarction: problems and prospects. Rus J Cardiol 2012; 1: 4-9.

6. Opie LH, Knuuti J. The adrenergic-fatty acid load in heart failure. J Am Coll Cardiol 2009; 54: 1637-46.

7. Leclercq IA, Da Silva Morais A, Schroyen B, Van Hul N, Geerts A. Insulin resistance in hepatocytes and sinusoidal liver cells: mechanisms and consequences. J Hepatol 2007; 47: 142-56.

8. Gruzdeva O, Uchasova E, Dyleva Y, Belik E, Kashtalap V, Barbarash O. Relationship between free fatty acids, insulin resistance markers, and oxidized lipoproteins in myocardial infarction and acute left ventricular failure. Diabetes, Metabolic Syndrome and Obesity: Targets and Therapy 2013; 6: 103-11.
9. Katagiri H, Yamada T, Oka Y. Adiposity and cardiovascular disorders: disturbance of the regulatory system. Consisting of humoral and neuronal signals. Circ Res 2007; 101: 27-39.

10. Mattu HS, Randeva HS. Role of adipokines in cardiovascular disease. J Endocrinol 2013; 216: 17-36.

11. Ertek S, Cicero A. Impact of physical activity on inflammation: effects on cardiovascular disease risk and other inflammatory conditions. Arch Med Sci 2012; 8: 794-804.

12. Katz A, Nambi SS, Mather K, et al. Quantitative insulin sensitivity check index: a simple, accurate method for assessing insulin sensitivity in humans. J Clin Endocrinol Metab 2000; 85: 2402-10.

13. Penn L, White M, Oldroyd J, Walker M, Alberti KG, Mathers JC. Prevention of type 2 diabetes in adults with impaired glucose tolerance: the European Diabetes Prevention RCT in Newcastle upon Tyne, UK. BMC Public Health 2009; 9: 342.

14. Franczyk-Skóra B, Gluba A, Banach M, Rysz J. Treatment of non-ST-elevation myocardial infarction and ST-elevation myocardial infarction in patients with chronic kidney disease. Arch Med Sci 2013; 9: 1019-27.

15. Stubbs PJ, Alaghband-Zadeh J, Laycock JF. Significance of an index of insulin resistance on admission in non-diabetic patients with acute coronary syndromes. Heart 1999; 82: 443-7.

16. Schwarz PE, Li J, Lindstrom J, Tuomilehto J. Tools for predicting the risk of type 2 diabetes in daily practice. Horm Metab Res 2009; 41: 86-97.

17. Grossman AN, Opie LH, Beshansky JR, Ingwall JS, Rackley $\mathrm{CE}$, Selker HP. Glucose-insulin-potassium revived: current status in acute coronary syndromes and the energy-depleted heart. Circulation 2013; 127: 1040-8.

18. Nolan CJ, Madiraju MSR, Delghingaro-Augusto V, Peyot ML, Prentki M. Fatty acid signaling in the beta-cell and insulin secretion. Diabetes 2006; 55: 16-23.

19. Poitout V, Hagman D, Stein R, Artner I, Robertson RP, Harmon JS. Regulation of the insulin gene by glucose and fatty acids. J Nutr 2006; 136: 873-6.

20. Prentki M, Joly E, El-Assaad W, Roduit R. Malonyl-CoA signaling, lipid partitioning, and glucolipotoxicity: role in beta-cell adaptation and failure in the etiology of diabetes. Diabetes 2002; 51: 405-13.

21. El-Assaad W, Buteau J, Peyot ML, et al. Saturated fatty acids synergize with elevated glucose to cause pancreatic beta-cell death. Endocrinology 2003; 144: 4154-63.

22. Tomas E, Tsao TS, Saha AK, et al. Enhanced muscle fat oxidation and glucose transport by ACRP30 globular domain: acetyl-CoA carboxylase inhibition and AMP-activated protein kinase activation. Proc Natl Acad Sci U S A 2002; 99: 16309-13.

23. Graham TE, Yang Q, Blüher M, et al. Retinol-binding protein 4 and insulin resistance in lean, obese, and diabetic subjects. N Engl J Med 2006; 354: 2552-63.

24. Sun L, Oi O, Zong G, et al. Elevated plasma retinol-binding protein 4 is associated with increased risk of type 2 diabetes in middle-aged and elderly chinese adults. J Nutr 2014; 144: 722-8.

25. Frangogiannis NG. The immune system and cardiac repair. Pharmacol Res 2008; 58: 88-111.

26. Hajer GR, Haeften TW, Visseren FL. Adipose tissue dysfunction in obesity, diabetes, and vascular diseases. Eur Heart J 2008; 29: 2959-71.

27. Ikezaki A, Hosoda $\mathrm{H}$, Ito $\mathrm{K}$, et al. Fasting plasma ghrelin levels are negatively correlated with insulin resistance and PAI-1, but not with leptin, in obese children and adolescents. Diabetes 2002; 51: 3408-11. 